\title{
NIEBLA EN AGOSTO (2016) Y LA SOMBRA DEL PASADO (2018). AKTION T4: EL PLAN DE EUTANASIA NAZI PARA LA ELIMINACIÓN DE LAS PERSONAS CON DISCAPACIDAD
}

\author{
Fog in August (2016) and Never look away (2018). Aktion T4: The nazi \\ euthanasia plan for the elimination of persons with disabilities
}

\author{
Francisco Javier DE PRADA PÉREZ \\ Centro de Salud Mental II-C -San Juan. Pamplona (España). \\ Correo electrónico: jdepradaperez@gmail.com
}

Recibido: 4 de febrero de 2021

Aceptado: 21 de abril de 2021

\section{Resumen}

El ascenso al poder del nacionalsocialismo en Alemania y sus consecuencias ha sido una fuente inagotable para la inspiración de producciones cinematográficas. Sin embargo, el programa Aktion T4 más conocido por plan de eutanasia nazi, no había sido tema principal de una película hasta fechas recientes. Niebla en agosto (2016) y La Sombra del pasado (2018) son dos cintas que abordan los métodos empleados para el control y eliminación de las personas con discapacidad o, mejor dicho, de aquellas personas que no cumplían los cánones de la raza aria y además eran una carga económica para el estado alemán. Las leyes de esterilización, primero, el programa de eliminación de bebés nacidos con alguna clase de discapacidad y, por último, el programa Aktion T4 que seleccionaba y ordenaba el asesinato de las personas ingresadas en instituciones son las tres fases de un calculado plan de exterminio. Psiquiatras, personal de enfermería y otros médicos y sanitarios fueron los diseñadores, colaboradores y ejecutores de ese crimen contra la humanidad que fue, sin duda, un ensayo para el posterior genocidio judío. Todavía hoy se reclama en Alemania verdad, justicia y reparación para las casi 300.000 personas víctimas de esos crímenes olvidados.

Palabras clave: eutanasia; nazismo; discapacidad; eugenesia; esterilización; ética.

\section{Abstract}

The rise to power of National Socialism in Germany and its consequences has been an inexhaustible source of inspiration for film productions. However, the Aktion T4 program, best 
known for a Nazi euthanasia plan, had not been the main subject of a movie until recently. Fog in august (2016) and Never look away (2018) are two films that address the methods used for the control and elimination of people with disabilities or, rather, of those who did not comply with the canons of the Aryan race and they were also an economic burden for the German state. The sterilization laws, first, the program for the elimination of babies born with some kind of disability and, finally, the Aktion T4 program that selected and ordered the murder of people admitted to institutions are the three phases of a calculated plan of extermination. Psychiatrists, nursing staff and other doctors and health workers were the designers, collaborators and executors of this crime against humanity that was, without a doubt, a trial for the subsequent Jewish genocide. Truth, justice and reparation for the almost 300,000 people of these forgotten crimes are still claimed in Germany today.

Keywords: euthanasia; Nazism; disability; eugenics; sterilization; ethics.

\section{Fichas técnicas}

Título: Niebla en agosto.

Título original: Nebel im August.

País: Alemania.

Año: 2016.

Director: Kai Wessel.

Música: Martin Todsharow.

Fotografía: Hagen Bogdanski.

Montaje: Tina Freitag.

Guión: Holger Karsten Schmidt sobre la novela homónima de Robert Domes.

Intérpretes: Ivo Pietzcker, Sebastian Koch, Thomas Schubert, Fritzi Haberlandt, Henriette Confurius, Branko Samarovski, David Bennent, Jule Hermann,Niklas Post, Karl Markovics.

Color: Color (Technicolor).

Duración: 126 minutos.

Género: drama, nazismo, II Guerra Mundial, infancia.

Idioma original: alemán.

Productora: Collina Film, Dor Film Wien, Studiocanal, ARRI Media Productions, Ernst Eberlein Filmproduktion, ZDF, Österreichischer Rundfunk (ORF), B.A. Produktion.

Sinopsis: Un niño de la comunidad yeniche es internado en un hospital psiquiátrico y experimenta el programa nazi de eutanasia. Consciente de lo que está ocurriendo y muy unido a sus amigos, el chico intentará sabotear el programa. (FILMAFFINITY).
Premios: Premios del Cine Alemán: Mejor actriz secundaria (Fritzi Haberlandt, 2016)

Enlaces: https://www.filmaffinity.com/es/ film851887.html; https://www.imdb.com/ title/tt4250566/

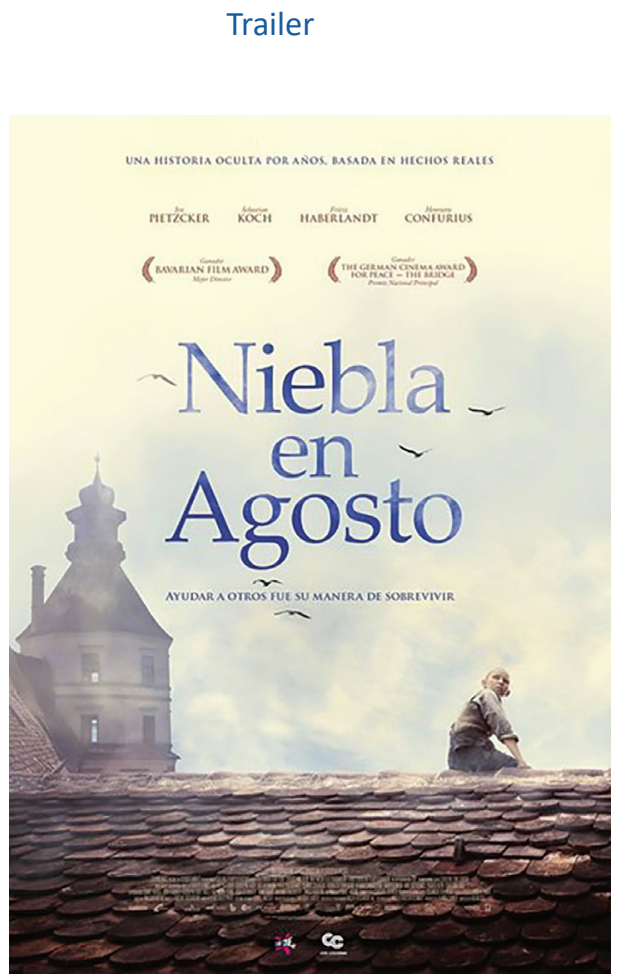

Cartel español de Niebla en agosto / Nebel im August de Kai Wessel (2106). 
Título: La sombra del pasado.

Título original: Werk ohne Autor.

País: Alemania.

Año: 2018

Dirección: Florian Henckel von Donnersmarck.

Música: Max Richter.

Fotografía: Caleb Deschanel.

Montaje: Patricia Rommel.

Guión: Florian Henckel von Donnersmarck.

Intérpretes: Sebastian Koch, Tom Schilling, Paula Beer, Saskia Rosendah, Oliver Masucci, Hanno Koffler.

Color: Color (Technicolor).

Duración: 188 minutos.

Género: drama, thriller, nazismo, biográfico.

Idioma original: alemán.

Productora: Co-production Alemania-Italia; Pergamon Film, Wiedemann \& Berg Filmproduktion, Beta Cinema, RAI Cinema, ARTE, Bayerischer Rundfunk (BR).
Sinopsis: Kurt Barnert es un joven estudiante de arte en la Alemania del Este. Está enamorado de su compañera de clase, Ellie. El padre de ella, el Professor Seeband, un famoso médico, no aprueba la relación de su hija y está decidido a destruirla. Lo que ninguno de ellos sabe es que sus vidas están conectadas por un terrible crimen cometido hace décadas. (FILMAFFINITY).

Premios: Premios Oscar: Nominada a mejor película de habla no inglesa y fotografía (2018), Globos de Oro: Nominada a Mejor película de habla no inglesa (2018), Premios del Cine Alemán: Nominada a Mejor actor secundario (Masucci, 2018).

Enlaces: https://www.filmaffinity.com/es/ film452842.html

https://www.filmaffinity.com/es/film452842. html

Trailer

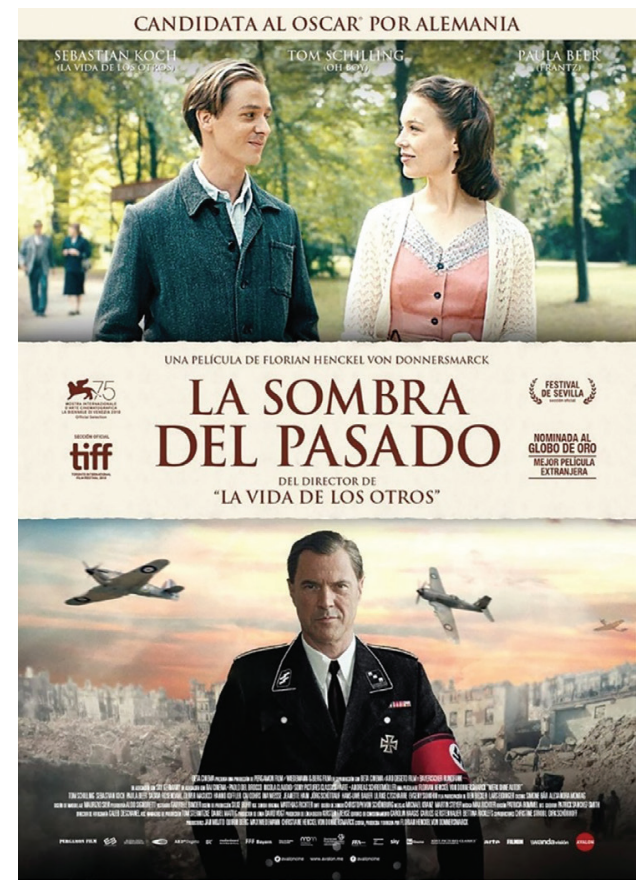

Cartel español de La sombra del pasado / Werk ohne Autor (2018) de Florian Henckel von Donnersmarck. 


\section{NIEBLA EN AGOSTO (2016) Y LA SOMBRA DEL PASADO (2018). AKTION T4 FRANCISCO JAVIER DE PRADA PÉREZ}

\section{Introducción}

El periodo histórico del nacionalsocialismo en Alemania ha sido llevado al cine con profusión y ha abordado muy diferentes enfoques. Obviamente predominan las películas que tratan el genocidio judío donde sin duda destaca por su popularidad La lista de Schindler / Schindler's list (1993) de Steven Spielberg. Sin embargo, son quizá Shoah / Shoah (1985) de Claude Lanzmann y El hijo de Saúl / Son of Saúl (2015) de László Nemes obras que ilustran con mayor hondura el holocausto. Otras abordan ópticas quizá menos exploradas como la participación de los 'kapos' judíos en la organización de los campos de concentración como La zona gris / The grey zone (2001) de Tim Blake Nelson o reflejan biografías marcadas por el nazismo como El pianista / The pianist (2012) de Roman Polanski. Hay incluso quien se adentra en el presunto silencio de la Iglesia católica ante el exterminio judío, como describe Amen / Amen (2012) de Costa Gavras, o construye una magnífica metáfora acerca del triunfo del amor sobre la barbarie como en La vida es bella / Life is beautiful (1997) de Roberto Benigni.

Es el nazismo, por tanto, un tema que parece inagotable para la producción cinematográfica $y$, sin embargo, hasta fechas recientes no había abordado, al menos de manera monotemática, el programa sistemático de exterminio de personas con discapacidad llevado a cabo por parte de la clase médica y de enfermería en ese mismo periodo. Alemania no cesa de sentarse en su particular diván para seguir con su psicoanálisis social y de nuevo se mira en el espejo de su tenebroso pasado gracias a dos directores alemanes que abordan el espinoso asunto: la participación de los sanitarios en el plan que pretendía la eliminación de quienes, para ellos, eran los miembros prescindibles por ser improductivos para la sociedad, pero a la vez eran los más indefensos.

Niebla en agosto / Fog in august (2016) de Kai Wessel y La sombra del pasado / Never look away (2018) de Florian Henckel von Donnersmarck son dos películas que se adentran en los métodos llevados a cabo para el siniestro fin. Ambas ilustran sin lugar a dudas la nauseabunda colaboración de la clase médica en la selección y ejecución de las víctimas para unos fines que hunden sus raíces en la denominada pureza racial a la que se le quiso dar una pátina de ciencia incuestionable. Casualmente es el mismo actor en ambas, Sebastian Koch, el encargado de dar verosimilitud al médico entregado a la causa nazi con plena convicción.

\section{Fundamentación ideológica para un asesinato en masa}

A la eclosión de ese "huevo de la serpiente», referido al programa de eliminación de personas con discapacidad, contribuyeron varios factores que actuaron de perfecta incubadora ideológica. El nacimiento entusiasta de la eugenesia como disciplina científica de perfeccionamiento social, el ascenso de un régimen racista que ponía énfasis en el poder hegemónico del Estado y, por último, la colaboración entre la clase médica y la judicial como cooperadoras necesarias en una práctica que quería tener apariencia benefactora.

La palabra eugenesia (eugenics «buena raza») fue acuñada por el inglés Francis Galton en 1883 a la sazón primo de Charles Darwin que había publicado en 1859 su famosa obra sobre el origen de las especies. La nueva disciplina era un medio técnico para mejorar la raza, pero a la vez era una cosmovisión que apostaba por medidas elitistas y discriminatorias que derivaron en un programa social de control de la natalidad apoyadas en el neomaltusianismo. La obsesión por la degeneración de la especie está en el pensamiento de Galton y sus seguidores.

Se generalizó la idea de que debía evitarse el nacimiento de las personas que, dejadas a su suerte por la selección natural que opera en el resto del reino animal, no tendrían posibilidades de seguir con vida. Todo se atribuye a la

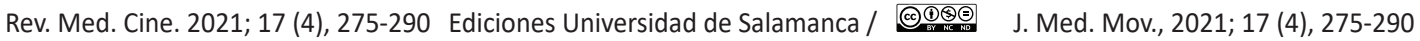
[ 278 ] 
herencia, tanto lo moral como lo fisiológico. Hay una descontextualización de las causas de los desequilibrios entre personas y una confianza ciega en ese análisis de los rasgos genéticos.

Se crearon sociedades eugenésicas en Gran Bretaña y en Estados Unidos. En este último se promulgaron leyes esterilizadoras hasta en 32 estados entre 1907 y $1937^{1}$. En el norte de Europa también fueron implantadas leyes esterilizadoras como en Dinamarca y Suecia. Sorprende comprobar cómo recientemente se ha procesado a Alberto Fujimori, ex presidente de Perú, por las más de 270.000 mujeres que fueron esterilizadas a la fuerza en ese país durante su segundo mandato, entre 1995 y 2000, dentro del Programa Salud Reproductiva y Planificación Familiar, en teoría destinado a combatir la pobreza².

Cabe recordar que hasta fechas recientes no entró en vigor en España la Ley Orgánica 2/2020 de 16 de diciembre ${ }^{3}$, que elimina del derecho español la posibilidad de esterilización forzosa o no consentida, previa autorización judicial, de las personas con discapacidad que tengan modificada su capacidad jurídica, en consonancia con la Convención sobre los derechos de las personas con discapacidad de 2006, vigente en España desde 2008.

\section{La esterilización masiva como primer peldaño}

Tan sólo cuatro meses después de las elecciones de marzo de 1933 en Alemania, el boletín del estado nazi publicaba una ley de esterilización denominada Ley para la prevención de las enfermedades hereditarias. Establece un listado de diagnósticos entre los que se puede encontrar: debilidad mental, esquizofrenia, locura bipolar, epilepsia, corea de Huntington, ceguera hereditaria, sordera hereditaria, además del alcoholismo grave. Sólo entre 1934 y 1935 se procedió a la esterilización de al menos 375.000 personas.

La base sobre la que se asienta el entramado jurídico nazi no ofrece lugar a dudas. La concepción teórica del pueblo alemán como un único organismo, en el que hay que evitar que nazcan y se reproduzcan células enfermas, provocará que se apruebe un corpus jurídico que se corresponde con los principios de una higiene racial que será llevada hasta sus últimas consecuencias. La esterilización fue el primer escalón de un «descenso a los infiernos», en una espiral de asesinatos en masa de inocentes, que será preámbulo de la 'Solución Final', que terminará con la vida de seis millones de judíos.

En La sombra del pasado/Never look away (2018), el Doctor Carl Seeband (Sebastian Koch) es el encargado de ordenar la esterilización de quien presuntamente padece una enfermedad mental que la inhabilita para tener descendencia. En este caso es el personaje Elisabeth May (Saskia Rosendahl), tía del pintor protagonista de la película.

El director de la cinta, Florian Henckel von Donnersmarck, conocido por la oscarizada $L a$ vida de los otros/The lives of others (2006), relata la historia del pintor ficticio Kurt Barnert (Tom Schilling) criado en la Alemania Nazi y en la postguerra de Berlín oriental. De niño, siempre interesado por el arte, visita una exposición del denominado por los nazis «arte degenerado» con su tía Elisabeth, que se convierte en su primera mentora y le deja una impronta sobre la autenticidad de lo bello. Ella sufrirá una crisis psicótica y será trasladada a una institución dirigida por el profesor Carl Seeband, prestigioso ginecólogo. Tras la tragedia de la guerra y todos los crímenes en ella cometidos, la trama se centra en la edad adulta del pintor, que trabaja como rotulista en la República Democrática Alemana. Allí conocerá y se enamorará de Ellie (Paula Beer), cuyo padre es el Doctor Seeband.

La película es una adaptación libre de la vida real del famoso pintor alemán Gerhard Richter que se casó con Marianne Eufinger en 1957. Años después descubrió que su suegro, Heinrich Eufinger, participó en esterilizaciones forzadas en Dresde como director de una clínica municipal de 
mujeres. Más tarde se conoció a través de un artículo de periódico que una tía suya murió en el programa de eutanasia. Fue uno de los primeros artistas plásticos de la posguerra en abordar la eutanasia en su obra.

El régimen nazi no sólo promovió medidas de evitación de nacimientos con esterilizaciones, sino que implantó el programa Lebensborn «fuente de vida», impulsado por Heinrich Himmler. Consistía en la apertura de casas de maternidad donde engendrar a hijos de mujeres con apariencia aria, emparejándolas con oficiales de las SS. No sólo en Alemania, el programa se puso en marcha en países como Noruega, Francia, Dinamarca o Polonia. La película Dos vidas / Two lifes (2012) de Georg Maas, aborda ese tema de forma brillante (Foto 1).

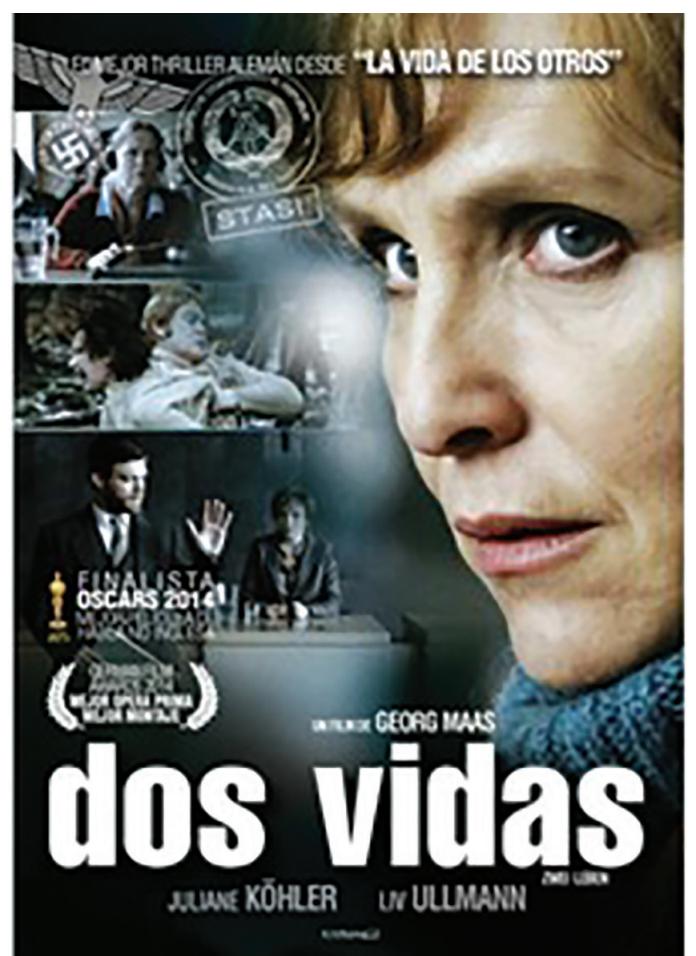

Foto 1. Cartel español de Dos vidas /Two lifes (2012) de Georg Maas.
El programa de eutanasia en Alemania para la pureza racial

Como advertencia terminológica, se emplea en este artículo la palabra 'eutanasia' debido a que fue el nombre que emplearon los ideólogos del programa de exterminio. Por ello, la bella palabra de etimología griega que alude a una «buena muerte» ha pasado a la historia manchada por el abyecto resultado que provocó la aplicación del programa que llevaba su nombre. Ese programa tenía poco que ver con un fallecimiento acorde con la dignidad humana. Muy al contrario, fue un metódico crimen contra la humanidad, en especial contra los más vulnerables, que fueron los primeros en inaugurar las cámaras de gas y los hornos crematorios.

Cuando se produce el ascenso del partido nazi al poder, en Alemania había ingresadas en instituciones de beneficencia unas 350.000 personas con discapacidad. Como se viene exponiendo, las autoridades disfrazaron sus intenciones con argumentos falaces, apoyados en una supuesta compasión bienintencionada y en el argumento de la necesaria justicia en el reparto de las cargas que reclamaba el pueblo alemán para intentar atajar su crisis económica.

Era preciso implantar un sistema que consolidara el biopoder, con un ejército de personal médico, de enfermería, psiquiatras y personal administrativo que eran los soldados del nuevo régimen. Sin embargo, su intención no era atender a un paciente concreto, sino que el verdadero paciente era la nación alemana en su conjunto. Eran los encargados de combatir, como "soldados biológicos» en palabras de Blázquez Ruiz ${ }^{4}$, a los enemigos internos y a los enemigos biológicos. Aquellos que no representaban el canon ario establecido como puro.

La obra que quizá tuvo mayor influencia para la justificación del programa fue la firmada en 1920 por el erudito psiquiatra Alfred Hoche, de Friburgo, y el profesor de Derecho Penal Karl Binding, de Leipzig. Tenía por título: «La autorización 
para el exterminio de las vidas sin valor vital $\varkappa^{5}$. Hay en ella una serie de calificativos a las personas con discapacidad como "seres humanos defectuosos, comedores inútiles, caparazones humanos vacíos». En ese opúsculo se alude al gasto que supone su mantenimiento y a que, la sociedad como organismo vivo, puede eliminar aquellas partes que están enfermas para salvar el todo.

Posteriormente, Adolf Hitler, en su obra Mein Kampf, tomará prestadas ideas de la eugenesia, del darwinismo social y de los autores citados y asegurará: "Quien no esté sano física y mentalmente no puede pretender inmortalizar su sufrimiento en su descendencia. A quien ya no posea la fuerza de luchar por su propia salud, se le negará el derecho a vivir en este mundo que supone una lucha constante».
A ese ensalzamiento de la perfección, que es un regreso a un neoplatonismo, contribuye sin duda el cine con la directora Leni Riefenstahl como figura destacada. Sus películas más famosas El triunfo de la voluntad / Triumph des Willens (1935) y Olympia (1938) son dos ejemplos de la culminación de la propaganda nazi.

Para lograr la adhesión al menos tácita de la población no se escatimaron medios en la producción de impresos y productos audiovisuales. En ellos se aportaban datos sobre el coste para las arcas públicas del cuidado de las personas con discapacidad (Foto 2).

El cortometraje Erbkrank / Hereditary disease $(1936)^{6}$ con imágenes reales de pacientes en hospitales psiquiátricos, es un ejemplo de los que se elaboraron en la Oficina de Política racial. Su visionado repugna la sensibilidad actual, pero está en

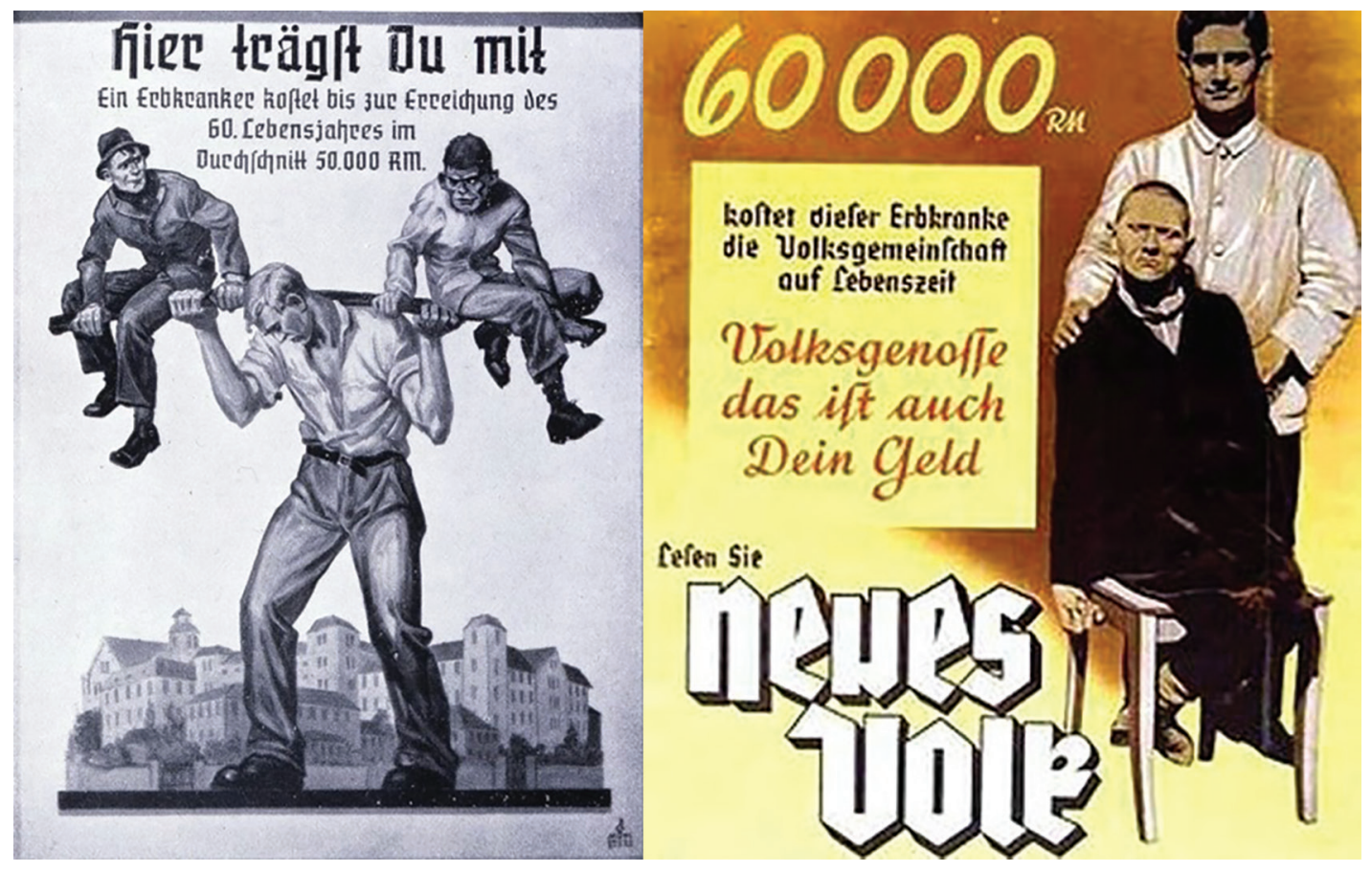

Foto 2. Cartelería utilizada para ilustrar el coste de la atención residencial. 
perfecta sintonía con la cosmovisión eugenésica y la supremacía neoplatónica de lo perfecto, de lo bello, de lo que carece de defecto. De hecho, en las imágenes se contrapone la monstruosidad de la persona con discapacidad con la belleza de los niños y jóvenes arios.

Se retoman postulados de la Grecia clásica, donde se aplicaba el infanticidio a los neonatos con alguna deformidad, una práctica aplaudida por filósofos como Aristóteles. En Esparta, adalid del culto al cuerpo sano, se lleva a cabo su máxima expresión. Sólo los más fuertes y brillantes estaban autorizados a seguir con vida. El recién nacido era expuesto ante un consejo de ancianos que, en caso de deformidad o tara, era arrojado desde el monte Taigeto ${ }^{7}$.

A lo largo de la historia se han distinguido diversos periodos en el tratamiento de las personas con discapacidad. De un modelo de prescindencia, en el que se practicó la eugenesia y la marginación, se pasó a un modelo médico rehabilitador que se inicia en el S. XVI con la creación de instituciones en el que se abordó la atención. Dicho periodo dura hasta el siglo XX en el que los autores ya hablan del nuevo modelo social de la discapacidad ${ }^{8}$, donde se pone el énfasis en las condiciones exteriores que generan las dificultades y no las inherentes del propio individuo. Sin embargo, al comienzo del siglo XX, la eugenesia retoma los postulados del modelo de prescindencia, es decir, el que prefiere seleccionar para evitar el nacimiento de los menos aptos. Es el periodo nazi el que lleva más lejos esa estrategia, puesto que opta por el modelo espartano de eliminación de los ya nacidos y, más adelante, también de las personas adultas con discapacidad.

Las primeras víctimas, por tanto, fueron los neonatos con aparentes malformaciones. Un Decreto confidencial de julio de 1939 introdujo la obligación a médicos, matronas y clínicas del país de informar sobre nacimientos con alguna anomalía. Se debía rellenar el cuestionario elaborado por las autoridades y enviarlo a un apartado de correos de Berlín, justo al lado de la cancillería del Reich.

Los casos detectados se enviaban a unas "unidades especiales de pediatría» las fatídicas Kinderfachabteilung, unas 25 abiertas por todo el país. A los padres se les tranquilizaba argumentando que se aplicaría un tratamiento curativo, cuando en realidad se procedía a administrar inyecciones letales. Es difícil calcular el número, pero los autores ${ }^{9}$ aportan cifras entre 1939 y 1945 de más de 5.000 niños asesinados con sobredosis de fármacos, principalmente con Luminal cuyo principio activo es el fenobarbital.

\section{Aktion T4: La orden directa de Hitler de iniciar el programa secreto}

No cabe duda de que el Estado nazi impone su particular concepción de la vida a través de las normas. La soberanía ya no descansa en el pueblo, sino en el Estado. De hecho, existe una inseguridad jurídica y ello se manifiesta en la existencia de un derecho secreto, que emana directamente del Führer y es valorado como superior en la escala normativa.

Ahí se inscribe el caso de la implantación del Programa Aktion T4 en el verano de 1939 por el que se inicia el asesinato de las personas con discapacidad: Una orden secreta de carácter interno firmada por Hitler, pero no publicada.

La puesta en marcha del programa adoptó todas las cautelas posibles. Theo Morell, médico de cámara de Hitler, elaboró la memoria «Exterminio de la vida indigna de ser vivida» en el verano de 1939. Esbozó una futura ley y calculó un ahorro de 10 millones de marcos anuales. «5.000 idiotas con un coste anual de 2.000 marcos» escribió ${ }^{10}$.

A partir de ese momento, Alemania inició su particular cruzada contra sus enemigos genéticos (Erbfeinde) en agosto de 1939 con el famoso documento firmado por Hitler en el que se establecía (Foto 3): 


\section{NIEBLA EN AGOSTO (2016) Y LA SOMBRA DEL PASADO (2018). AKTION T4 FRANCISCO JAVIER DE PRADA PÉREZ}

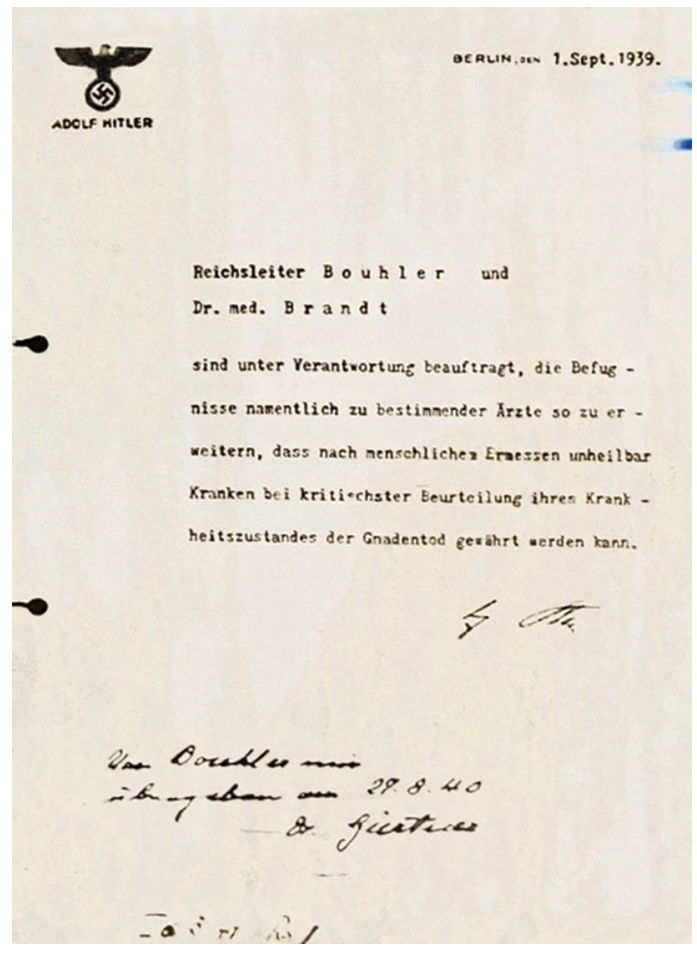

Foto 3. Documento de inicio de la Aktion 4 firmada por Hitler.

Delego en el director de la cancillería, Phillip Bouhler y en el doctor en medicina, Karl Brandt para que, bajo su responsabilidad, autoricen nominalmente a determinados médicos garantizar, según criterios humanitarios y después de valorar el estado de su enfermedad, la muerte por compasión de todos aquellos enfermos incurables.

De este modo, se inicia la denominada Gnadentod o "muerte compasiva», un minucioso plan de exterminio coordinado desde el número 4 de la calle Tiergarten de Berlín. De ahí proviene su nombre en clave: Aktion T4.

La selección se produjo, como en el caso de la eutanasia infantil, enviando cuestionarios que debían rellenarse en las instituciones. Era obligatorio identificar a aquellos pacientes que:

\section{Padecen las siguientes enfermedades y}

además no participan en las actividades del hospital o sólo son capaces de trabajos mecánicos como barrer: Esquizofrenia, epilepsia, demencia senil, retraso mental de cualquier tipo, encefalitis, corea de Huntington y otras enfermedades neurológicas terminales.

2. Aquellos que llevan ingresados 5 años ininterrumpidamente.

3. Los catalogados como enfermos criminales,

4. Los que no posean nacionalidad alemana o no pertenezcan a la raza nórdica. En ese caso es necesario indicar su raza y nacionalidad.

Una vez llegaban los expedientes, tres médicos los revisaban y marcaban un recuadro que decidía el futuro del afectado. Una cruz roja significaba la muerte; la azul, la vida; y un interrogante, la duda con futura revisión.

Alguien puede verse tentado a imaginar que el asesinato de las personas con discapacidad se aplicó a quienes en los establecimientos se hallaban encamados, con mínimo contacto con su entorno o con una enfermedad que se podría calificar como incapacitante o terminal. Sin embargo, existen abundantes testimonios desgarradores, como relata Götz Aly en su sobra "Los que sobraban». Todos ellos relatados en primera persona, tanto de enfermos que lograron escapar en el último momento del gaseamiento, como de personal de instituciones, que cuentan las horrorosas experiencias de la llegada de autobuses con las ventanillas opacas de la Gekrat, la compañía de autobuses encargada de recoger a los pacientes para su traslado. Sobrecogen los gritos de súplica de quienes eran arrastrados a ellos. Este episodio queda perfectamente ilustrado en Niebla en agosto, cuando uno de los residentes es perseguido por las salas para conseguir llevarlo al autobús.

Tan sólo la acción de algunas familias logró, con su insistencia, que sus parientes lograran esquivar un destino mortal. El resto recibió una carta en la que se comunicaba la «muerte 
inesperada». La policía local tenía la orden expresa de incinerar los cadáveres y enviar las cenizas. Se añadía una ilustrativa frase: "Su muerte significa una liberación de sus sufrimientos, ya que padecía una enfermedad incurable.»

El método empleado fue el gas monóxido de carbono. Se construyeron estancias en los sótanos de los edificios donde posteriormente se incineraban los cuerpos. Este proceso queda ilustrado de manera impactante en La sombra del pasado en el que un grupo de personas son conducidas por el propio personal de enfermería a la sala en la que serán gaseadas con la plena confianza en que esas profesionales velan por su seguridad y salud $y$, en cambio, las conducen a la muerte inmediata. Queda claro que quien abre la llave del gas venenoso es un sanitario, como así lo exigía la burocracia.

El hallazgo por parte de un militar norteamericano en el Castillo de Hartheim de la estadística siniestra del programa puso cifras a la barbarie. Hubo al menos seis establecimientos encargados de estos asesinatos:

\begin{tabular}{|l|r|}
\hline LOCALIDAD & CIFRA \\
\hline Grafeneck & 9.839 \\
\hline Ciudad de Bradenburgo & 9.772 \\
\hline Benburg & 8.601 \\
\hline Hadamar & 10.072 \\
\hline Hartheim & 18.269 \\
\hline Sonnenstein (Pina) & 13720 \\
\hline TOTAL & $\mathbf{7 0 . 2 7 3}$ \\
\hline
\end{tabular}

El más mortífero fue Hartheim, hoy convertido en Memorial. Se puede visitar en Austria y es estremecedora la experiencia de recorrer sus sótanos donde se puede leer los nombres de quienes fueron allí asesinados. Es muy esperanzador comprobar cómo otras salas del centro recogen multitud de fotos actuales de personas con discapacidad plenamente integradas en la sociedad en clara contraposición con lo que allí ocurrió. Allí se grabaron varias escenas de Niebla en agosto (Fotos 4 y 5).

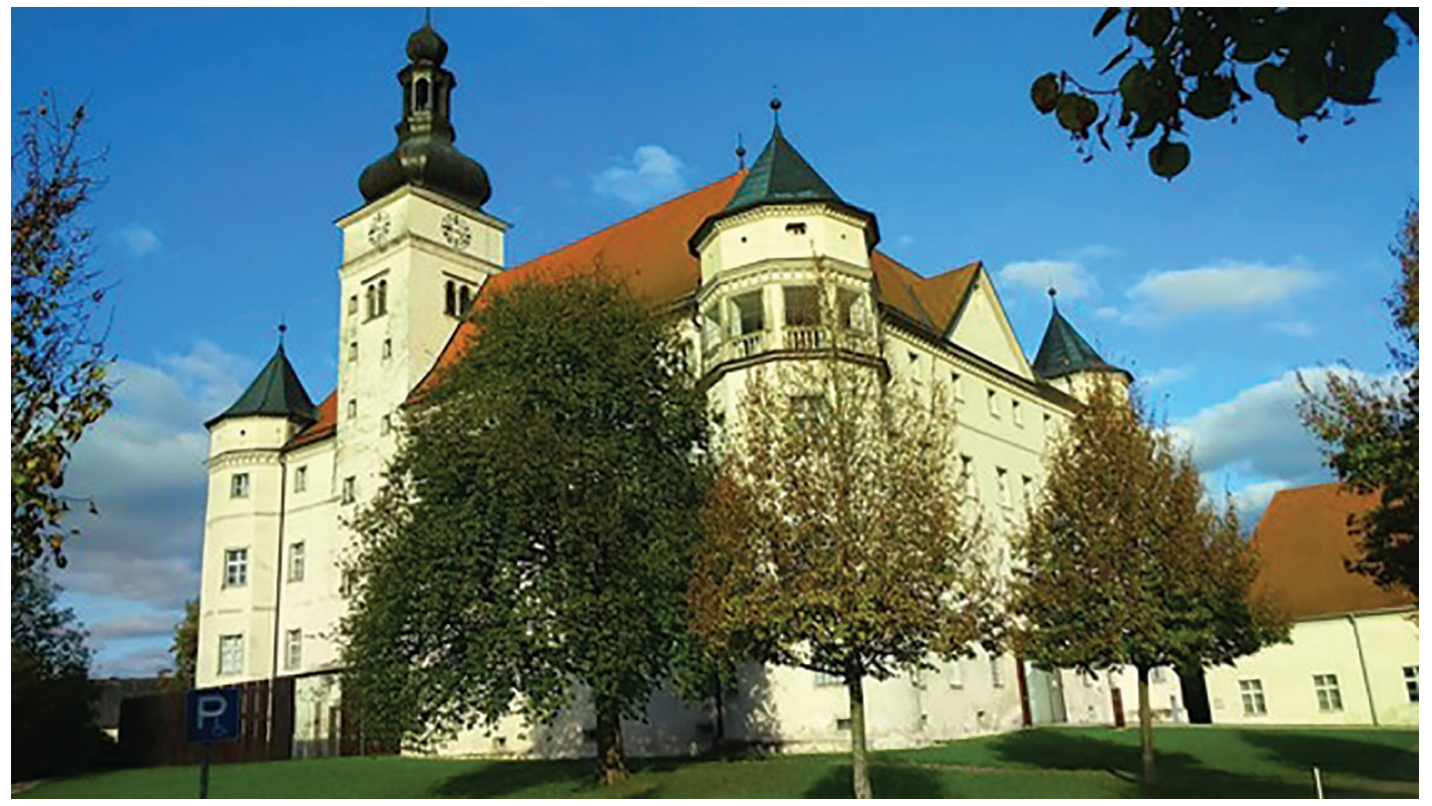

Foto 4. Castillo de Hartheim. Vista exterior. 


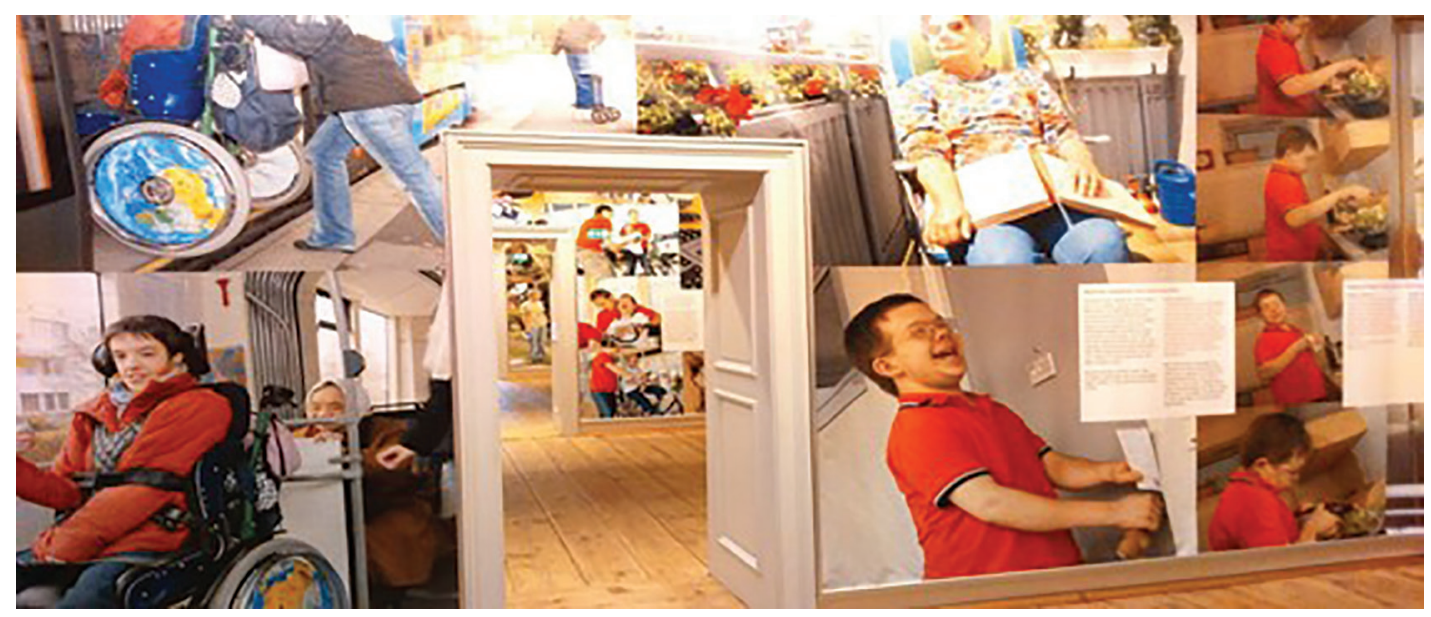

Foto 5. Castillo de Hartheim. Salas interiores.

La presión social y de la Iglesia logra paralizar el programa

La paralización del programa obedeció a varios factores, entre ellos la catastrófica campaña militar en la Unión Soviética, aunque también resultó decisiva la intervención del Obispo de Münster, Clemens August Graf Von Galen, quien con su denuncia pública de lo que estaba ocurriendo provocó que Hitler ordenara que cesara de inmediato la Aktion $\mathrm{T}^{11}$.

Sus valientes homilías en la catedral en el verano de 1941 lo denunciaban abiertamente, con las bombas británicas ya cayendo sobre la ciudad. Desde el púlpito calificó la desaparición de pacientes de las instituciones como un rotundo homicidio. Von Galen fue respetado por el régimen debido a su prominencia, pero varios de sus empleados fueron arrestados. Lo mismo le sucedió al deán de la catedral de Berlín, Bernhard Lichtenberg, quien fue detenido por la Gestapo tras su protesta pública y murió camino al campo de concentración de Dachau.

En este punto cabe resaltar que en 2005 el obispo Von Galen fue beatificado en Roma por Joseph Ratzinger, el papa Benedicto XVI, quien había relatado que un primo suyo con síndrome de Down fue una de las víctimas de la Aktion T4 en su país natal.

A la eutanasia nazi le seguirán otras atrocidades que no harán sino aumentar la perversidad de una maquinaria de muerte perfectamente engrasada. El método utilizado para la eliminación es muy simbólico. Como afirma Primo Levi «Había que usar y se usó el mismo gas venenoso que se usaba para desinfectar las estibas de los barcos infestados de chinches o piojos ${ }^{12}$. Tampoco es casual que las personas con discapacidad fueran marcadas como ganado para el matadero, con un rotulador rojo entre los omóplatos.

Por tanto, como también ocurrió con los judíos que fueron comparados con las ratas, había que despojar a las personas con discapacidad de todo vestigio de humanidad, de toda condición de persona, para luego aplicar el mismo tratamiento que se daría a una plaga de animales nocivos. Es, como señala el mismo autor, la aversión contra quien es diferente. En el caso de las personas con discapacidad, esa diferencia era en ocasiones indisimulable.

Hubo un intento del régimen de conseguir la aprobación popular mediante películas como la célebre Ich Kluge an / I accuse (1941), en la que 
se presenta como éticamente loable la necesidad de aplicar la eutanasia en casos de largas enfermedades sin posibilidad de curación (Foto 6).

\section{Descentralización y continuación del programa de exterminio}

La orden de Hitler no hizo sino cambiar la estrategia del programa y lejos de enlentecer su maquinaria, la descentralizó y aceleró su mortan-

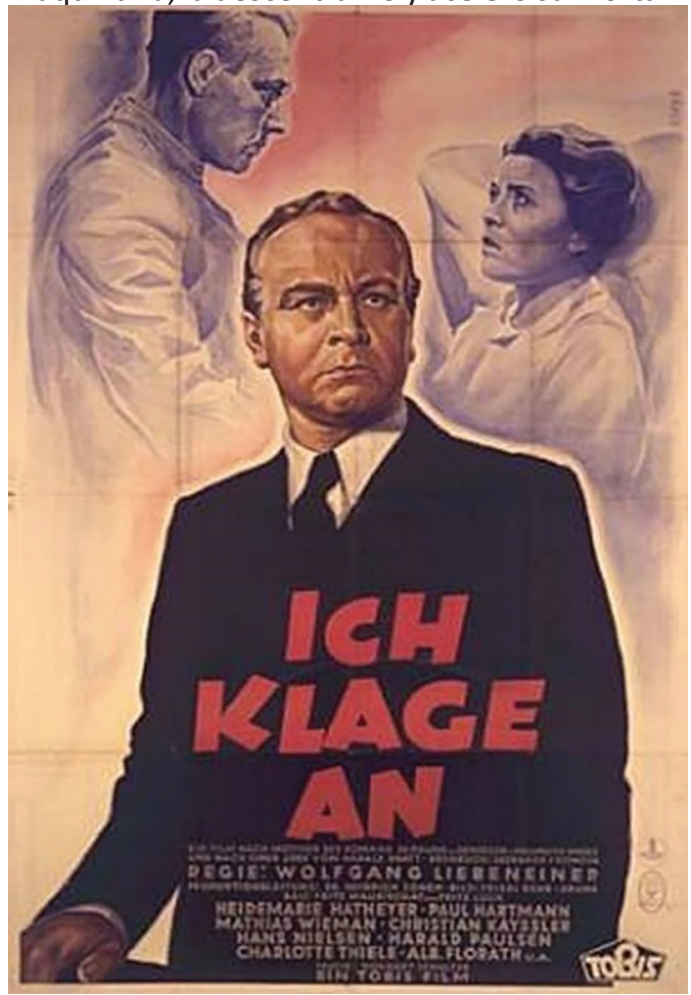

Foto 6. Cartel en alemán de la película Yo acuso / I accuse (1941).

dad. Se nombró a un Comisario del Reich para los establecimientos de Curación y Cuidados sólo dos meses después, el Dr. Herbert Linden.

Así, por ejemplo, en la cámara de gas de Hartheim todavía siguieron asesinando hasta el final de la guerra muchos miles de presos, sobre todo del campo de concentración de Mauthausen, situado a sólo 40 kilómetros. Está documentado que al menos 449 españoles perdieron allí la vida. Como anécdota, Miguel Juste, un albañil español que sobrevivió para contarlo, fue obligado a participar en las obras que intentaban borrar las pruebas de lo que allí ocurrión ${ }^{13}$.

No en vano, la experiencia adquirida en la Aktion T4 hizo que muchos de sus funcionarios fueran destinados a la puesta en marcha de campos de exterminio como Belzec, Sobibor o Treblinka. De hecho, por indicación directa de Himmler, en la primavera y verano de 1941 un grupo de médicos de la T4 liderados por Heyde y Nitsche relizaron visitas a los campos de concentración de Sachenhausen, Auschwitz, Buchenwald, Mauthausen, Dachau, Ravensbrück, Gros-Rosen, Flossenburg y Neuengamme para la selección de quiénes serían enviados a las cámaras de gas ${ }^{14}$.

Este proceso se desarrolló bajo la abreviatura burocrática de Acción 14f13. Un «tratamiento especial» en el que el número 13 corresponde al monóxido de carbono. Durante la segunda mitad de la guerra alrededor de 100.000 personas fueron víctimas en establecimientos públicos alemanes cuyo fin inicial era cuidar y curar. Hay autores que elevan a casi 300.000 las víctimas si se suman las acciones criminales llevadas a cabo en territorios invadidos de Francia, Polonia y Rusia.

En ocasiones no se provocaba la muerte directa, sino que se sometía a los pacientes a otros métodos como dejar morir por inanición con la denominada Hungerkost o "dieta de hambre». Esta fase queda perfectamente ilustrada en la película Niebla en agosto, cuando el Dr Werner Veithausen celebra una reunión con otros colegas en la que sirve una sopa que, a pesar de tener sabor, carece de cualquier propiedad alimenticia. Lo presenta como un descubrimiento para dejar morir de una manera menos traumática, o al menos así lo cree. En esa escena, el jerarca nazi presente expone los principios nítidos de su ideología: «Ese tercio inferior debe ser eliminado para que nuestro pueblo pueda volver a desarrollarse 
sobre unos cimientos sanos. El pueblo alemán no está dispuesto a seguir pagando».

Niebla en agosto está basada en la verdadera historia de Ersnt Lossa, interpretado por Ivo Pietzcker, un niño yeniche, nómada, que los nazis consideraban gitanos. Su madre murió cuando tenía cuatro años y su padre fue llevado a Dachau con dos de sus hermanos en 1939. Vivió con sus dos hermanas Anna y Amalie en diferentes hogares infantiles. Fue calificado como «alimaña antisocial, rebelde y mentiroso" y fue admitido en el sanatorio y hogar de ancianos de Kaufbeuren en abril de 1942.

En Kaufbeuren, el niño era popular entre los cuidadores y las enfermeras debido a su forma sociable y servicial, razón por la cual se dice que algunos de ellos se negaron a matarlo más tarde. Poco después de su llegada a Kaufbeuren, Ernst se percató de las muertes de los enfermos, según aparece en la película. Resultaba molesto porque intentó evitar la labor asesina del personal, robaba comida y alimentaba a otros niños para salvarlos del hambre. Debido a este comportamiento, el director médico del centro, Valentin Faltlhauser, ordenó su eliminación. Fue asesinado el 9 de agosto de 1944 con una inyección letal en mitad de la noche, a la edad de 14 años. Era un niño perfectamente sano ${ }^{15}$ (Foto 7).

En la película también se menciona la intención de enviar los cerebros a otra institución. En 2017 se anunciaba en prensa que la Sociedad Max Planck de Berlín había puesto en marcha una investigación independiente para identificar, por primera vez, a todas las víctimas cuyos cerebros laminados, más de dos mil, siguen en
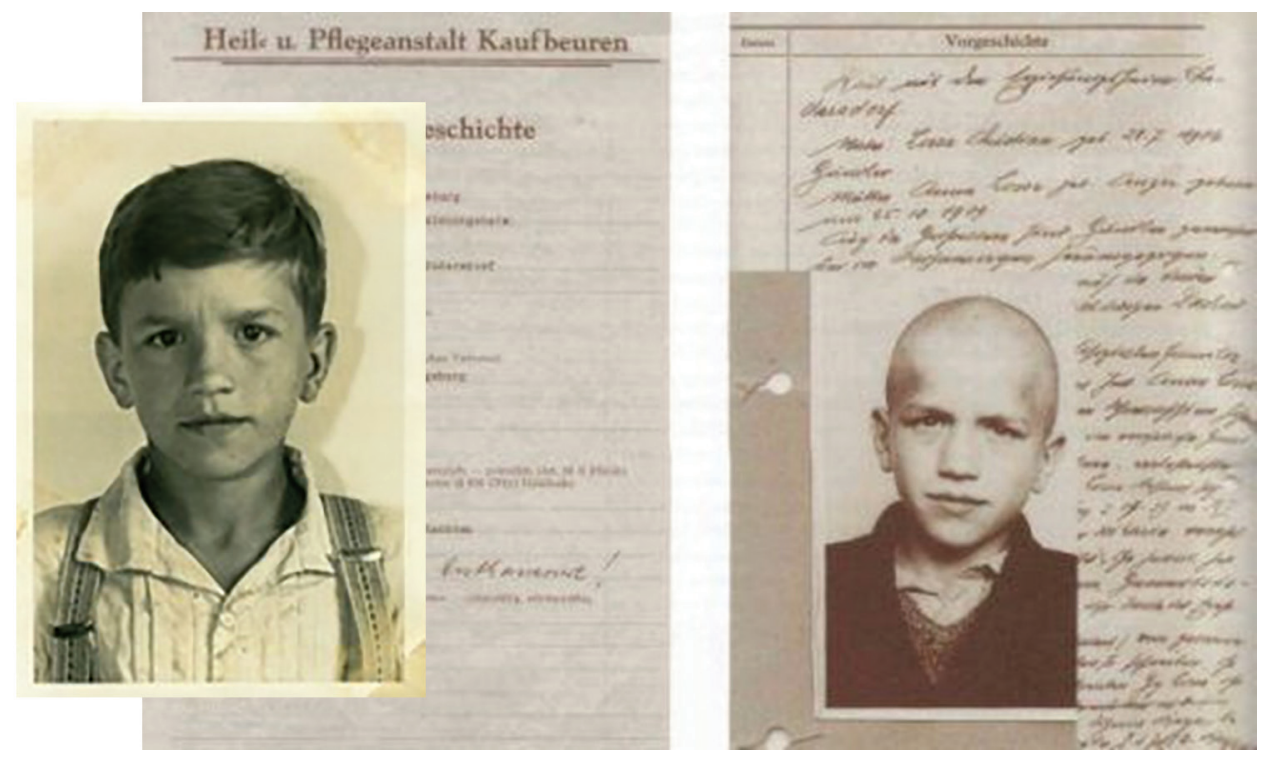

Foto 7. Ficha de ingreso de Ernst Lossa.

los archivos de este organismo de investigación científica, uno de los más prestigiosos del país ${ }^{16}$.

Con el avance de la guerra y las derrotas en el este había órdenes de desalojar las instituciones en zonas amenazadas por los ataques aéreos y habilitar camas para los heridos. Para finales de 1942 las matanzas pasaron a manos de las propias SS ya en el interior de los campos de concentración. En ellos se sustituyó el monóxido de carbono por Zyklon B, un agente desinfectante utilizado para el control de plagas. 


\section{El Proceso judicial y el Código de Nuremberg}

El tribunal internacional que se constituyó para juzgar los crímenes contra la humanidad del Tercer Reich sentó en el banquillo de los acusados a una veintena de médicos, entre los que se encontraba Karl Brandt, médico personal de Hitler y uno de los máximos responsables del programa de eutanasia. Fue ejecutado en la horca en 1948 en la prisión de Lansdberg.

Sin embargo, en la memoria colectiva quizá han pervivido en la historia los testimonios de los macabros experimentos llevados a cabo por el Dr. Mengele más que la aniquilación masiva de las personas con discapacidad, que se había producido mucho antes de que la maquinaria de muerte de los campos se pusiera en marcha. De ahí que el colectivo de personas con discapacidad afirme que las primeras 70.000 personas que pasaron por los hornos crematorios son unos crímenes olvidados que merecen su propio lugar en la historia y no diluidos en el gigantesco holocausto judíi ${ }^{17}$. Sorprende de hecho que no haya sido hasta septiembre de 2014 cuando en Berlín se inauguró un monumento en el lugar desde donde se organizó el programa de eutanasia, en el número 4 de la Tiergartenstrasse (Foto 8).

En 2017, en el Bundestag, la cámara baja del Parlamento alemán, se llamó a rescatar del olvido a las 300.000 víctimas de la eutanasia. Su presidente, Norbert Lammert, señaló que uno de los aspectos indignantes es que la eutanasia nacionalsocialista no forma parte de la memoria colectiva y calificó como estremecedora la indiferencia mostrada durante años por la ciencia, los medios y la política. Recordó que solo una pequeña parte de los médicos y personal sanitario implicado en los asesinatos fue juzgado.

Quizá los campos de concentración fueron confiados a sádicos, a personajes embrutecidos por la disciplina militar y la guerra. Aunque esta afirmación no es compartida por la filósofa Hanna

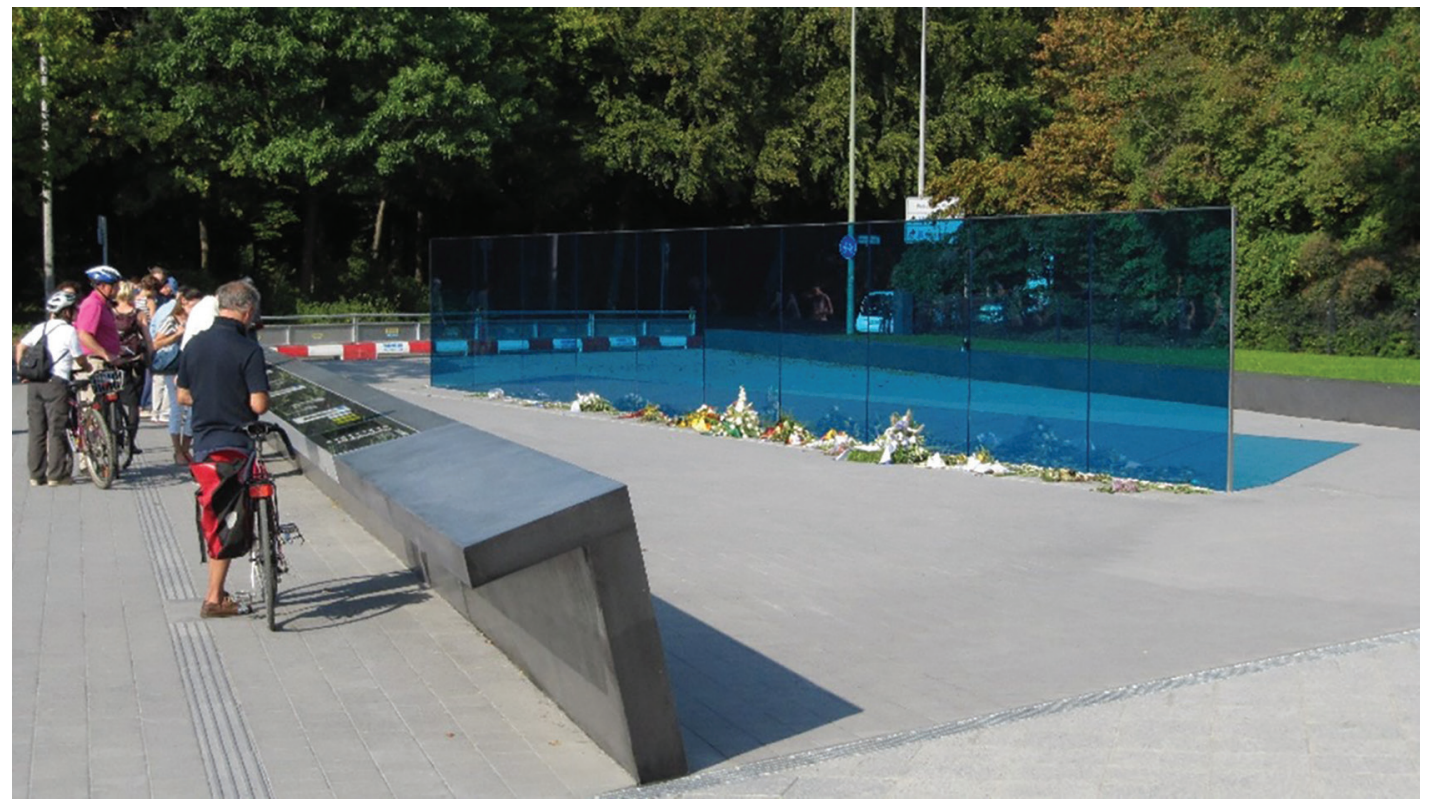

Foto 8. Monumento conmemorativo en el número 4 de Tiergartenstrasse en Berlín. 
Harendt. Ella sostiene, en su teoría de la banalidad del mal, que el holocausto fue practicado por personas corrientes, burócratas y funcionarios, que se limitaron a ejecutar con minuciosidad germánica las órdenes de superiores sin apenas cuestionarlas. Por ello afirma que Eichmann, lugarteniente de Hitler, era de hecho una persona corriente, en la medida en que no era especialmente malvada. La autora afirma que bajo las condiciones del Tercer Reich, sólo se podía esperar que reaccionaran con heroicidad las personas excepcionales ${ }^{18}$.

De ahí que sea más inaceptable que la eutanasia fuera ejecutada por profesionales de la medicina y de la enfermería, personas presuntamente formadas y cuya ética les debería haber hecho dar un paso atrás. Todo lo contrario, fueron premiados económicamente por su labor. En el manicomio de Hadamar, por ejemplo, se celebró una fiesta al llegar a las 10.000 víctimas. Fueron muy contados los casos que se negaron a esa colaboración.

En la película Niebla en agosto, la enfermera Sophia Oberschwester (Fritzi Haberland) es un ejemplo de resistencia individual a la obediencia debida. En ella operaba la culpa moral que describió Jaspers $^{19}$, la que apela a la propia conciencia y no cabe escudarse en la cadena de mando jerárquica (salvo en casos de chantaje con peligro para la propia vida). Ella le dice al director médico una frase que ilustra nítidamente esa idea: «En este mundo hay leyes de más alto rango que las de su Führer» Siguiendo al mismo autor, cabe señalar la culpabilidad criminal de muchos profesionales sanitarios que obedecieron a otros muchos culpables políticos.

\section{Iniciativa Hartheim contra el olvido}

A modo de corolario, la muy reciente Iniciativa de conmemoración de las víctimas de la «eutanasia» que se firmó en el Castillo de Hartheim el 28 de junio de $2019^{20}$, expresa varias exigencias que ilustran algunas cuestiones todavía pendientes entre las que destacan:
«Numerosos sanatorios, hogares de ancianos e instalaciones para personas con discapacidad estuvieron involucrados en los crímenes. La mayoría de estas instituciones todavía se utilizan hoy para tratar y acompañar a las personas. En estas instalaciones, las antiguas escenas del crimen deben ser tratadas con dignidad y se deben encontrar formas adecuadas de recuerdo. Es necesaria una discusión pública sobre si es éticamente y terapéuticamente justificable continuar tratando y cuidando a los pacientes hoy en las habitaciones donde tantas personas fueron cruelmente asesinadas.

Los nombres de las víctimas deben publicarse en una forma apropiada en todo el país y en un contexto local. La sociedad está obligada a proporcionar los fondos necesarios para encuestas y publicaciones. Las biografías de las víctimas deben escribirse sin diagnósticos médicos ni descripciones degradantes, a menos que estén cuidadosamente clasificadas.

Las direcciones médicas de las instalaciones en las que se produjeron los delitos entre 1933 y 1945 son las encargadas de informar al público y de brindar atención individual a los familiares. No basta con entregar un historial médico archivado a los familiares. Más bien, necesitan ayuda para comprender el contexto histórico, los términos técnicos, su clasificación histórica y -esto es muy importante para nosotros - apoyo emocional en el enfrentamiento con el destino específico y la situación familiar en ese momento. Estas instituciones deben indicar un contacto para familiares en su sitio web.

Hasta el día de hoy, los perpetradores de crímenes de «eutanasia» nazis son honrados mediante membresías honorarias, cruces de mérito federal o nombres de calles. Exigimos un ostracismo público de los perpetradores al retirar estos honores.»

Según el cálculo de Götz Aly, las más de 200.000 víctimas de la eutanasia nazi estarían emparentados en línea directa con al menos diez millones de alemanes (y austriacos) actualmente vivos. 


\section{NIEBLA EN AGOSTO (2016) Y LA SOMBRA DEL PASADO (2018). AKTION T4 FRANCISCO JAVIER DE PRADA PÉREZ}

\section{Conclusión}

La cinematografía había obviado en la extensa producción acerca del periodo nazi el programa de exterminio sistemático de las personas con discapacidad. Niebla en agosto y La sombra del pasado han abordado con crudeza ese momento histórico que precedió al holocausto judío, pero que sin duda fue un ensayo, tanto en los métodos utilizados para su ejecución como en la utilización de la ideología de la supremacía racial para llevarlo a cabo. Sin embargo, en esa primera etapa, la participación de la clase médica y de enfermería fue un aspecto diferencial y, quizá más sorprendente desde el punto de vista ético, pues eran profesiones que debían velar por la protección de la salud, especialmente, la de los más vulnerables. La historia ha soslayado ese aspecto y ha sido en época ya muy recientes cuando han ido surgiendo iniciativas en memoria y reconocimiento de esas víctimas concretas.

\section{Referencias}

1. Cambrón Infante A. La eugenesia y sus sombras. En: Blázquez Ruiz FJ, director. 10 Palabras clave en nueva genética. Estella: Verbo Divino; 2006. p. 255.

2. Fowks J. La Fiscalía peruana denuncia a Fujimori por el escándalo de las esterilizaciones forzosas. El País. 2 de marzo de 2021.

3. España, Cortes Generales. (2020) Ley Orgánica 2/2020, de 16 de diciembre, de modificación del Código Penal para la erradicación de la esterilización forzada o no consentida de personas con discapacidad incapacitadas judicialmente. Boletín Oficial del Estado 17-12-2020, 328, 115646- 115649.

4. Blázquez Ruiz FJ. La muerte compasiva en el régimen nacional socialista. En: Alenza García JF, director y Arcos Vieira ML, directora. Nuevas perspectivas Jurídico-éticas en Derecho Sanitario. Cizur Menor: Aranzadi; 2013. p. 492

5. García Marcos JA. La medicina sin rostro humano: «Eutanasia» y Experimentos. Médicos durante el Tercer Reich. Medicina e Historia; 2005.
6. Youtube.com [Internet] Zeitgeschichtliche Filmdokumente. Erbkrank.1936. c2021 [consultado el 3 de febrero de 2021]

7. Aguado Díaz AL. Historia de las deficiencias. Madrid: Escuela Libre Editorial Fundación ONCE; 1995. p. 48.

8. Palacios A. Romañach J. El modelo de la diversidad. La bioética y los derechos humanos como herramientas para alcanzar la plena dignidad en la diversidad funcional. Madrid: Ediciones Diversitas. AIES; 2006.

9. Friedlander $\mathrm{H}$. The origins of nazi genocide: From Euthanasia to the Final Solution. Chapel Hill: The University of North Carolina Press; 1995. p. 61.

10. Götz, A. Los que sobraban. Barcelona: Crítica; 2014. p. 26.

11. García Marcos JA. La eutanasia en la Alemania Nazi y su debate en la actualidad. Valencia: UNED; 2009. p. 180.

12. Levi, P. Si esto es un hombre. Barcelona: Muchnik Editores; 1995. p. 109.

13. Hernández de Miguel, C. Los últimos españoles de Mauthausen. Barcelona: Ediciones B; 2015. p. 285.

14. Wachsmann, N. KL Historia de los campos de concentración nazis. Barcelona: Crítica; 2015. p. 283.

15. Raueiser S. Ernst Lossa aus Augsburg (Bayern) 1929-1944. gedenkort-t4.eu [Internet] 15 de octubre de 2019 [consultado el 13 de marzo de 2021]

16. Domínguez, N. Alemania reabre el caso de los asesinados por la ciencia nazi. El País. 22 de mayo de 2017.

17. Disability Rights Advocates. Forgotten Crimes. The Holocaust and People with Disabilities.[Internet] septiembre 2001 [consultado el 9 de abril de 2021]

18. Young-Bruehl E. Hannah Arendt: Una biografía. Barcelona: Paidós; 2006.

19. Jaspers, K. El problema de la culpa. Pensamiento contemporáneo. Barcelona: Paidós; 2011. p. 53.

20. Hartheim-Deklaration Gedenkinitiative für die Euthanasie Opfe. [Internet] junio 2019 [consultado el 21 de abril de 2021] 